\title{
A Progress Report on the g-2 Storage Ring Magnet System*
}

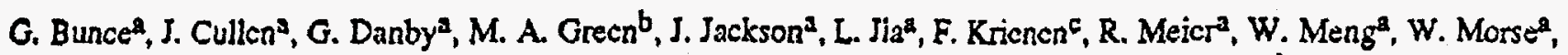 \\ C. Paia, I. Polkª, A. Prodella, R. Shuta ${ }^{2}$, L. Snydstrupa, and A, Yamamotod
}

a. Brookhaven National Laboralory, Uplon NY 10973, USA,

b. Lawrence Berkelcy Laboratory, Bcrkeley CA 94720 , USA

c. Boston University, Boston MA 02215, USA

d. KEK Laboralory, Japan

\begin{abstract}
The $3.1 \mathrm{GeV}$ muon storage ring for the g-2 experiment at Brookhaven National Laboratory her three large solenoid magnets that form continuous 1.451 tesla storage ring dipolo with an average beam bend radios of 7.1 meters. In addition to the three storage ring solenoids, there is an Inflector dipole with nested dipole coils that cresto very littlo stray magnetic fjeld. A superconducting shield on the inflector gets rid of most of the remaining stray flux. This paper reports on the progress made on the storage ring solenold magnet gystem and the inflector as of June 1995. The results of eryogenic system tests are briefly reported.
\end{abstract}

\section{BACKGROUND}

An cxperiment to measure the value of $g-2$ for the muon is under construction at the Brookhaven National Latoratory in Upton New York, USA[1,2]. The $g-2$ expcriment magnet system consists of three large superconducting solcnoid magnets that form a storage ring, a supcrconducting intlector magnet for injecting the muon beam into the storage ring. and a string of conventional bending and quadrupole magnets that are used to carry a decaying pion beam from a fixed target at the Brookhaven $33 \mathrm{GeV}$ Alternating Gradient Synchrotron (AGS) to the storage ring that is located in a building some distance from the AGS.

The focus of this report is the storage ring with its three large superconducting solenoids and the superconducting inflector dipole. There are two 24 turn inner solenoids that have a coil diameter of 13.4 meters and a single 48 tum outer solenoid that has a coil diameter of 15.1 meters. The three solenoids are the largest diameter superconducting solenoids that have been built to date. The curent in the two innes solenoids will be run in opposition to the current in the outcr solenoid creating the storage ring dipole field. An iron return yoke in the shape of a $C$ returns the magnetic flux. Separate iron pole pieces control the quality of the 1.451 tesla induction in the gap. The inlegrated induction around the storage ring must be grod to $1 \mathrm{ppm}$ within a $90 \mathrm{~mm}$ diameter region that contains the muon beam [3].

Manusctipt receivad 12 June 1995 * This work was performed with the support of the Office of High Energy and Nuclear Physics, U.S. Dept. of Energy under contract DE-AC02-76CH00016.
The open part of the $C$ points inward so the electrons that result from the decay of the muons (muons at rest have a decay half life of about 60 microseconds) will spiral inward to the detectors for the experiment. The beam enters the storage ring from the outside through a hole in the outcr solencid between the two 24 tum coils that are mounted on the outer solcnoid cold mandrel. An artists conception of the storage ting and $\mathrm{g}-2$ experiment detectors system is shown in Figure?

Al the ring entrance, a superconducting $D C$ inflector will locally cancel the field of the main storage ring magnet so that the muon bean crters, as closcly as possible, tangentially to the equilibrium orbit of the storage ring. The inlector magnet is designed to "eat" its own flux so that stray field from the inflector is grcatly reduced. In addition the inflector has a superconducting shield so that virtually all of the rcmaining stray field from the inflector is eliminated.

\section{PROGRESS ON THE g-2 SOLENOID MAGNETS}

Construction of the g-2 solenoids and their cryostats is complete 44 . The outer solcnoid has been mounted on the lower part of the iron yoke. The iron back $\mathrm{leg}$ of the $\mathrm{C}$ and the upper part of the iron yokc has been mounted around the outer solenoid cryogenic vacuum vessel. The two inner solenoids have been mounled on the iron yole as shown in Figure 2. The basic parameters of the three solcnoids mounted in the iron is given in Table 1.

\section{TABLE I PARAMETERS OF THE $\mathrm{g}-2$ SOLENOID MAGNETS IN THE IRCN}

Iron Height (min)

1570.

Iron Width (mm)

1394

Iron Mass for the Ring (metric tons)

681.6

Naminal Beam Bend Radius (m)

Numbar of Solenoid Packages

Pole Width (mm)

7.112

3

Nominal Gap betwcen the Poles (mm)

560.0

Dipole Ceniral Induction (T)

Number of Tums

Coil Current* $(\Lambda)$

Magnet Self Inductance (H)

180.0

Storige Dipole Slored Energy* (M)

5300

Total Solenoid Cold Mass (metric lons)

* at the design central induction
$-6.2$ 


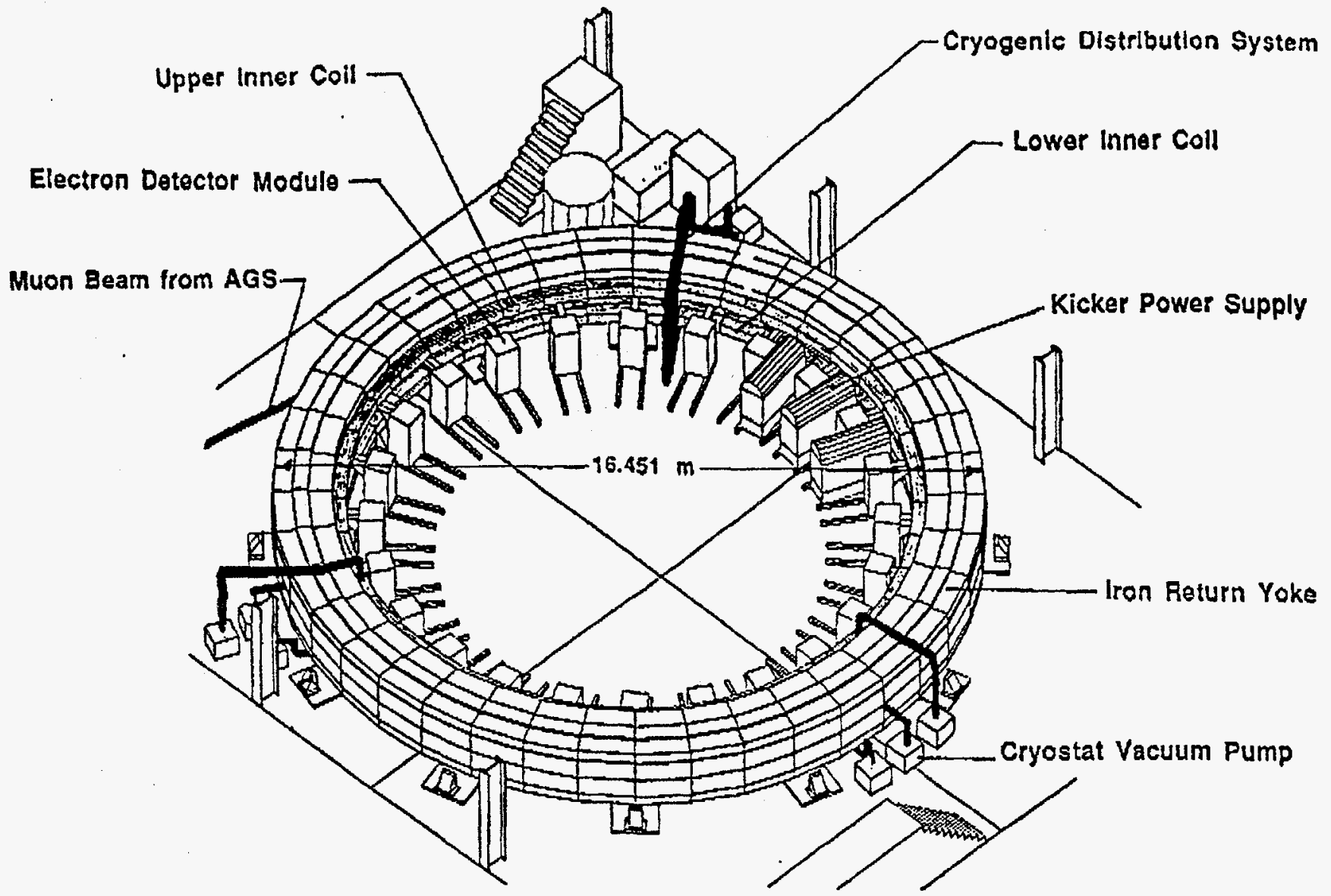

Fig. 1. An Artists Conception of the g-2 Experiment with the Detectors in Place

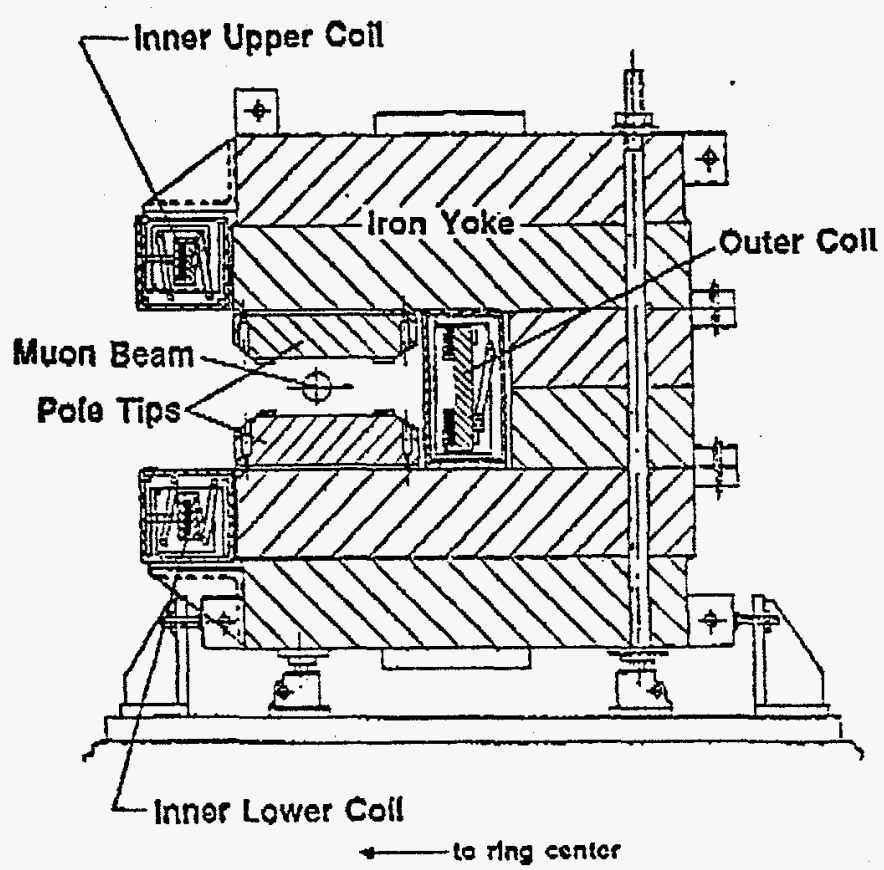

Fig. 2 A Cross-section View of the Storage Ring

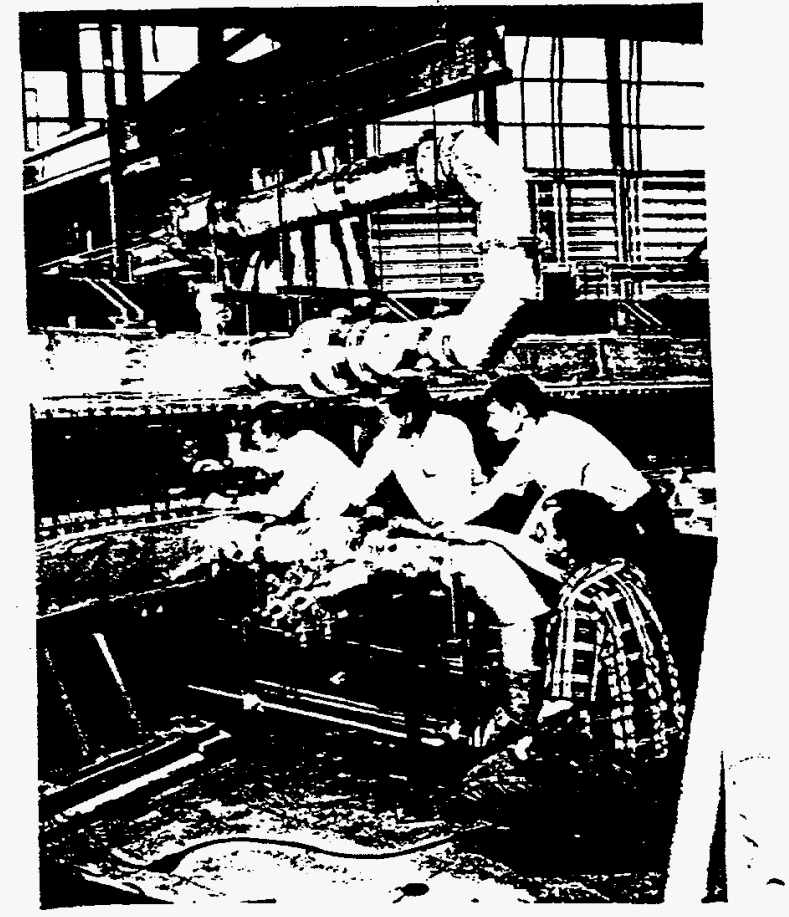

Fig. 3 The g-2 Storage Ring Dipole from the Inside 


\section{DISCLAIMER}

This report was prepared as an account of work sponsored by an agency of the United States Government. Neither the United States Government nor any agency thereof, nor any of their employees, make any warranty, express or implied, or assumes any legal liability or responsibility for the accuracy, completeness, or usefulness of any information, apparatus, product, or process disclosed, or represents that its use would not infringe privately owned rights. Reference herein to any specific commercial product, process, or service by trade name, trademark, manufacturer, or otherwise does not necessarily constitute or imply its endorsement, recommendation, or favoring by the United States Government or any agency thereof. The views and opinions of authors expressed herein do not necessarily state or reflect those of the United States Government or any agency thereof. 


\section{DISCLAIMER}

Portions of this document may be illegible in electronic image products. Images are produced from the best available original document. 
Fig 3 shows the assembled ring iron with the three solenoids mounted on the iron. The two inner solenoids are clearly visible in Fig. 3, and the pole pieces that shape the field have been installed. The outer coil cryostat is buried in the iron retum yoke. The clearance between the iron poles and the outer solenoid cryostat is small (as small as $6 \mathrm{~mm}$ ). This means that the outer coil cryostat vacuum vessel should not be too cold. In general, this is only a problem when the outer cryostat vacuum vessel is filled with helium at a pressure above 20 torr. The effect of cryostat vacuum vessel pressure on the temperature of the vacuum shell was measured during a cryogenic test of the outer solcnoid.

A cryogenic test of the outer solenoid package was performed before the cryostat was buried. The outer coil was cooled from room temperature $(294 \mathrm{~K})$ to about $150 \mathrm{~K}$ using nitrogen gas mixed with liquid nitrogen boil off gas. At some point when the mandrel temperature was below $150 \mathrm{~K}$, liquid nitrogen was used to cool the coil down to $80 \mathrm{~K}$. It took about 115 hours to cool the outer coil package from 294 $\mathrm{K} 1080 \mathrm{~K}$. The coil cool down from $80 \mathrm{~K}$ to the point where the outer coil became supercondlucting used liquid helium from dewars. It took 135 hours to cool the coil from $80 \mathrm{~K}$ until the magnct was superconducting

The resistance of the coil dropped about a factor of 10 as the coil cooled from $294 \mathrm{~K}$ to $80 \mathrm{~K}$. The coil rcsistance dropped another factor of 220 as the coil cooled from $80 \mathrm{~K}$ to $10 \mathrm{~K}$ The RRR of the uitra pure aluminum matrix material has remained above 2000 despite the cold work induced in the conductor during winding. As the mandrel temperature dropped below $9.5 \mathrm{~K}$, the coil became superconducting. The coil was fully superconducting when the average mandrel temperature reached $8.7 \mathrm{~K}$.

The lowest temperature achieved in the outer coil was about $7 \mathrm{~K}$. At that point, the liquid helium supply was exhausted. The measured heat leak into the outer solenoid mandrel was a little over 50 watts. This value is consistent with the heat leak calculations.

\section{PROGRESS ON THE INFLECTOR MAGNET}

The inflector is a truncated dipole that is desizned to cancel storage ring ficld so that the beam can enter the storage ring tangentially as closed as possible to the equilibrium orbit. The coil is a double cosine theta coil that minimizes the fringe field by cancellation of current distributions[5]. The field generated within the bore of the inflector is carricd between the two coils. The cancellation of the fringe field is not complete, so a supcrconducting shicld that remains superconducting within the storage ring field is used to cancel the rest of the fringe field generated by the inflector dipole. The $\mathrm{g}-2$ inflector is 1.7 mcters long. It operates at a current of $2850 \mathrm{~A}$ while in the field of the storage ring. The inflector stored energy at its full design curnent is about $9 \mathrm{~kJ}$. A cross-section vicw of the inflector is shown in Fig 4

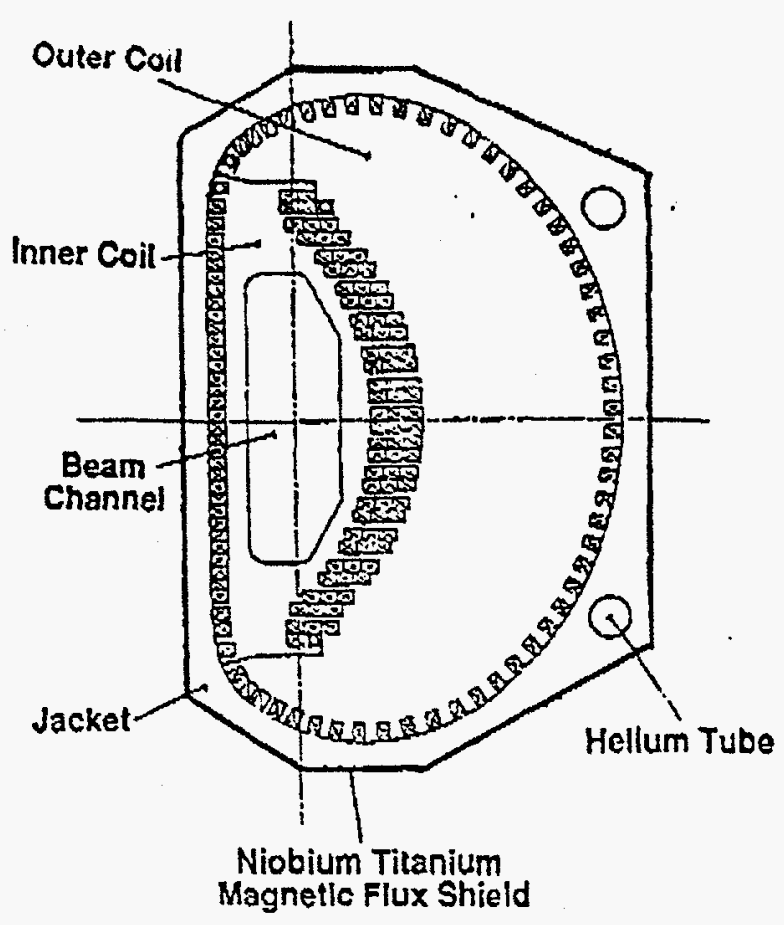

Fig. 4 A Cross-section of the g-2 Inflector Dipole

A one third length inflector was built at KEK in Japan using an aluminum based superconductor that was devcloped for a magnet used in a balloon astrophysics experiment. The $\mathrm{g}-2$ inflector surcrconductor is also stabilized using very pure $R R R=750$ aluminum. The one third scale model inflector was tested at KEK and Brookhaven with and without the superconducting shield. The test inflector operated at its design current in zcro field and in a uniform background induction of 1.5 tesla.

The magnetic shield that consists of alternating layers of $\mathrm{Nb}-\mathrm{Ti}, \mathrm{Nb}$ and $\mathrm{Cu}$ successfully reduces the stray field that was generated by the inflector. If the proper cooling cycle is used on the inflector (The inflector is kept above $10 \mathrm{~K}$ whilc the storage magnet charges to its full design field. Then the infector is cooled to $4.5 \mathrm{~K}$ ) the shieids will keep the stray flux so low the integrated field error around the ring due to the inflector will be below one part in a million. Over the period of the inflector cold test, (over an hour), there was no recorded decay in the circulating currents in the shield.

The full length inflector winding, potting and assembly of the two coils was completed by KEK in Japan in March of 1995. The inflector shield, developed by Nippon Sieel Corporation was installed on the coil package in the spring of 1995. Shipment of the fully asscmbled inflector magnet in its cryostat to Brookhaven is expected in the summer of 1995. The inflector will be installed in the ring during the fall of 1995. The inflector will be tested along with the test of the magnct system in early 1996. Final shimmirg of the storage ring magnet, with the infloctor in place, will occur in the first half of 1996 . The position of the end of the inflector in the storage ring is shown in Fig 5. 


\section{THE CONVENTIONAL MAGNET SYSTEM}

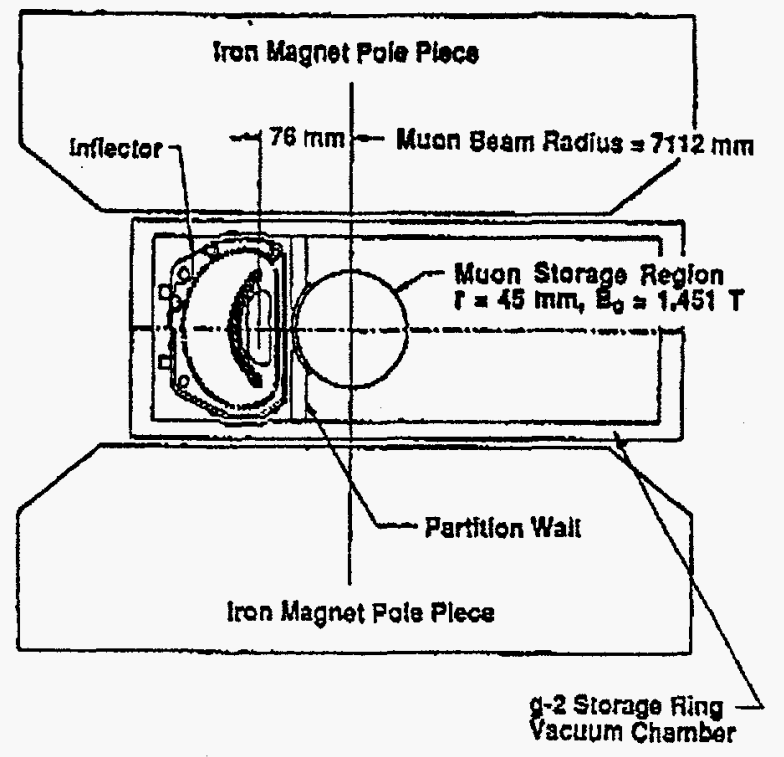

Fig 5. Inflector Cross-section in the Storage Ring (at the injection point)

\section{CRYOGENIC SYSTEM TEST}

The g-2 superconducting magnets will be cooled by a refrigerator built during the 1970s. This refrigerator was designed with a maximum capacity of $700 \mathrm{~W}$ when it is supplied with 120 grams per second of helium at a pressure of $1.8 \mathrm{MPa}$. The refrigerator was tested in 1994 using a single screw compressor that delivered 83 grams per second to the machine. The refrigeration and liquefaction were measured in a dewar located about 50 meters from the refrigerator. The refrigerator was connected to the load through a pair of unshielded transfer lines with bayonet joints about every 10 meters. The refrigerator delivered 450 watts of refrigeration to the load and it would liquefy over 4 grams per second of helium. The refrigerator performance appears to be more than satisfactory. With a pair of screw compressors that deliver 50 grams per second of helium at 1.6 to 1.8 $\mathrm{MPa}$, the refrigerator should produce 625 watts (at the cold box). The expected heat load for the $8-2$ cryogenic system is from 350 to 420 watts depending on the safety margin used in the heat load calculations[6].

Construction and leak checking of the cryogenic distribution system used to cool the g-2 storage ring magnels and the inflector will be finished in June of 1995. A cryogenic test of the complete magnet system will be done during the summer of 1995 . It is expected that the magnet system will be powered during the late summer of 1995. Magnet testing and shimming will oceur in late 1995. The control system for the magnets and their refigeration system will be installed in late 1995
The conventional magnet system for the g-2 experiment consists of a string of bending magnets and quadrupoics that direct a bcam of pion from the AGS target to the storage ring. The string of dipole and quadrupole magnets was installed during the spring of 1995 . The beam transport system will be operable before the first pion beam is transported to the storage ring in early 1996.

\section{CONCLUSION}

The superconducting solenoids are fabricalcd and in place in the $\mathrm{g}-2$ storage ring. The outer solenoid has been successfully cooled to $7 \mathrm{~K}$ using liquid nitrogen and liquid helium. The measured heat leak into the outer solenoid mandrel is very close to that predicted by calculation.

The one third length superconducting inflector was sucecssfully tested. The superconducting shicld performed well. Virtually all of the stray magnetic flux generated by the inflector was contained within the shield. When complete, the full length inflector will be shipped to the Brookhaven National Laboratory in the summer of 1995.

The g-2 refrigerator was lested and found to be satisfactory for the experiment. The cryogenic system hookup for the solenoids and the inflector will be complete in June of 1995. A full cryogenic system test will be finished in the summer of 1995

\section{ACKNOWLEDGMENT}

This work was performed with the support of the Office of High Energy and Nuclear Physics, United States Department of Energy under contract numbers DE-AC0276SF00016 and DE-AC03-76SF00098..

\section{REFERENCES}

[1] "Muon g-2 Design Report," Brookhaven National Laboratory, Upton NY 11973, AGS 821, April 1994

[2] The g-2 Collaboration, "The g-2 Storage Ring Superconducting Magnet Systcm," IEEE Transactions on Magnetics MAG-30, No. 4, p 2423 (1994)

[3] G. T. Danby and J. W. Jackson, "Shimming Techniques for the Ultraprecisc Muon g-2 Storige Ring at the AGS, IEEE Transactions on Magncties MAG-30, No. 4, P 1710 (1994)

[4] G. Bunce et al., The Large Superconducting Solenoids for the g-2 Ring." to be published in IEEE Transactions on Applied Supcrconductivity S, No. 2 (1995)

[5] F. Krienen et al., "The Superconducting Inflector Dipole for the $g .2$ Muon Sturage Ring." to be published in IEEE Transactions on Applied Superconductivity S, No. 2 (1995)

[6] L. $X$. Iis et a!, "Cryogenics for the Muon g-2 Superconducting Magnet System," to be published in the Proceedings of the 15h Inlernational Cryogenic Engineering Confetence, Genos, Ituly, 7-10 June 1994 